Aksaray University
Journal of Science and Engineering
e-ISSN: 2587-1277
http://dergipark.gov.tr/asujse
http://asujse.aksaray.edu.tr

Research Article

\title{
Determination of Possible Effects of Air Pollutants for the Kocaeli-Dilovasi
}

\author{
Saliha Cetinyokus* \\ Gazi University, Technical Sciences Vocational School, Department of Chemistry and Chemical Processing \\ Technology, Ankara 06374, Turkey
}

\begin{abstract}
In the study, it is aimed to determine the possible effects of air pollutants $\left(\mathrm{CO}, \mathrm{SO}_{2}, \mathrm{NO}, \mathrm{NO}_{2}\right.$, $\mathrm{O}_{3}$ ) in the Kocaeli-Dilovasi region where the industry is concentrated with ALOHA software. In the modeling studies, air pollutant concentration data for the years 2010 and 2017 of the National Air Quality Monitoring Network established by the Ministry of Environment and Urban Planning was used. Modeling studies were conducted through direct source and instant release scenarios. Toxic effects were identified for all air pollutants and the largest impact areas were identified for the toxic zone. For $\mathrm{NO}$ and $\mathrm{NO}_{2}$, the effect distance was determined to be $10 \mathrm{~km}$ in red (>20 ppm, PAC-3), orange (>12 ppm, PAC-2) and yellow (0.5 ppm, PAC-1) every two years. The worst-case scenario was considered with the selection of the atmospheric $\mathrm{F}$ stability class. Toxicity as well as combustion and explosion effects were determined for CO air pollutant. For the year 2010, the flammable region, red $(>75000 \mathrm{ppm}, 60 \% \mathrm{LEL})=2.2 \mathrm{~km}$ and yellow $(>12500 \mathrm{ppm}, 60 \% \mathrm{LEL})=$ distance of $4.7 \mathrm{~km}$ effects were obtained. It was determined that the detonation explosion effects gave larger impact distances $(<3 \mathrm{~km})$ and showed all explosion effects of the destructions of buildings ( $>8 \mathrm{psi})$, serious injury likely $(>3.5$ psi), and shatters glass (>1.0 psi). It was indicated that concentrations for $\mathrm{CO}$ and $\mathrm{O}_{3}$ air pollutants declined in 2017 and so resulted in a decrease in all impact values. It has been predicted that environmental regulations could be more effective if quantitative assessments of the possible effects of air pollutants were made.
\end{abstract}

\section{Keywords}

Air pollutants, effect distance, ALOHA software

*Corresponding Author: s.saliha@gmail.com, salihakilicarslan@gazi.edu.tr 


Aksaray University
Journal of Science and Engineering
e-ISSN: 2587-1277
http://dergipark.gov.tr/asujse
http://asujse.aksaray.edu.tr

Research Article

\title{
Kocaeli-Dilovası için Hava Kirleticilerinin Muhtemel Etkilerinin Belirlenmesi
}

\author{
Saliha Çetinyokuş*
}

Kimya ve Kimyasal İşleme Teknolojileri Bölümü, Gazi Üniversitesi, Ankara 06374, Türkiye

\section{Özet}

Çalışmada, sanayinin yoğunlaştığı Kocaeli-Dilovası'nda hava kirleticilerinin $\left(\mathrm{CO}, \mathrm{SO}_{2}, \mathrm{NO}\right.$, $\mathrm{NO}_{2}, \mathrm{O}_{3}$ ) muhtemel etkilerinin ALOHA yazılımı ile belirlenmesi amaçlanmıştır. Modelleme çalışmalarında, Çevre ve Şehircilik Bakanlığı tarafindan oluşturulan Ulusal Hava Kalitesi İzleme A ğı, 2010 ve 2017 yıllarına ait hava kirletici konsantrasyon verileri kullanılmıştır. Doğrudan kaynak ve anlık boşalma senaryosu üzerinden modelleme çalışmaları yürütülmüştür. Tüm hava kirleticileri için toksik etkiler belirlenmiş ve en geniş etki mesafeleri toksik bölge için bulunmuştur. $\mathrm{NO}$ ve $\mathrm{NO}_{2}$ için her iki yılda kırmızı (>20 ppm, PAC-3), turuncu (>12 ppm, PAC-2) ve sarı (0.5 ppm, PAC-1) bölgede $>10 \mathrm{~km}$ etki mesafesi belirlenmiştir. Atmosferik F kararlılık sınıfı seçimi ile en kötü durum senaryosu dikkate alınmıştır. CO hava kirleticisi için toksik etkiler yanında yanma ve patlama etkileri belirlenmiştir. Yanabilir bölgede 2010 yılı için, kırmıı $(>75000 \mathrm{ppm}, \% 60$ LEL) $=2.2 \mathrm{~km}$ ve sar1 $(>12500 \mathrm{ppm}, \% 60$ LEL $)=4.7 \mathrm{~km}$ etki mesafeleri elde edilmiştir. Detonasyon kaynaklı patlama etkilerinin daha geniş etki mesafeleri $(<3 \mathrm{~km})$ verdiği ve bina yıkılması $(>8 \mathrm{psi})$, ciddi yaralanma olasılığı $(>3.5 \mathrm{psi})$, cam kırılması (>1.0 psi) basınç etkilerinin tamamını gösterdiği belirlenmiştir. 2017 yılında $\mathrm{CO}$ ve $\mathrm{O}_{3}$ hava kirleticileri için konsantrasyonların düştüğü buna bağlı olarak tüm etki mesafesi değerlerinin azaldığ 1 tespit edilmiştir. Çevresel düzenlemelerin hava kirleticilerinin muhtemel etkilerinin kantitatif olarak değerlendirilerek yapılmasının, daha etkili sonuçlar verebileceği ön görülmüştür.

\section{Anahtar Kelimeler}

Hava kirleticileri, etki mesafesi, ALOHA yazılımı

*Sorumlu Yazar: s.saliha@gmail.com, salihakilicarslan@gazi.edu.tr 


\section{GİRİ̧̧}

Hava kirliliği son dönemde dünyanın en büyük çevresel sağlık riski haline gelmiştir. Dünya Sağlık Örgütü (WHO), 2012 yılında yaklaşık olarak 7 milyon insanın (tüm küresel ölümlerin 1/8'i) hava kirliliği sebebiyle öldüğünü raporlamıştır. Künzli ve arkadaşları, Avusturya, Fransa ve İsviçre' de açık hava ortamı ve trafik kaynaklı hava kirliliğinin halk sağlığı üzerine etkisini incelemiştir. Hasta olma oranı (morbidite) ve ölüm oranı (mortalite) ile ilgili olgular tahmin edilmiştir. Hava kirliliğinin yılda toplam ölüm oranının \%6'sını oluşturduğu ve bu ölümlerin yaklaşık yarısının motorlu trafikten kaynaklandığı belirtilmiştir [1]. Hien ve arkadaşları tarafından Doğu Asya kış musonlarının hava kirliliği vakalarına etkisi araştırılmıştır. 20032004 kışında kirlilik ve kış musonu arasında yakın ilişki belirlenmiş, çalışmanın WPE (winter pollution episodes) erken uyarı ve 24 saatlik kirletici konsantrasyonunun tahmini için faydalı olacağı belirtilmiştir [2].

Hava kirletici bileşenler, $\mathrm{CO}, \mathrm{SO}_{2}, \mathrm{NO}, \mathrm{NO}_{2}, \mathrm{NO}_{\mathrm{X}}, \mathrm{O}_{3}$ ve katı partiküllerdir. Literatürde bu hava kirletici konsantrasyonlarının analizi üzerine çok sayıda çalışma bulunmaktadır. Serbula ve arkadaşları tarafından $\mathrm{SO}_{2}$ ve katı partikül (As, $\mathrm{Pb}$ ve $\mathrm{Cd}$ ) dağılımı, ulusal ve uluslararası hava kalite yönergeleri üzerinden maden-metalurji sektörü için değerlendirilmiştir [3]. Zhang ve arkadaşları tarafından ozon/partikül madde (PM2.5) arasındaki ilişki ve bunlar üzerine sıcaklık, bağıl nem ve rüzgar hızı gibi meteorolojik parametrelerin etkisi araştırılmıştır [4]. Bachtiar ve arkadaşları tarafından Endonezya'da bulunan Padang şehri ortam havasındaki $\mathrm{O}_{3}$ konsantrasyonu analiz edilip haritalandırılmıştır. Bunun için, şehirdeki 52 noktada 1 saatlik ölçümler alınmıştır. Sonuçlar, Endonezya Hükümeti Yönetmeliğinde belirtilen kalite standartlarının altında belirlenmiştir [5]. Kyoto Protokolü, $\mathrm{CO}_{2}$ emisyonlarının sanayileşmiş ülkelerde azaltılmasını zorlamaktadır. Bunun için en etkili yol, sanayi fırınlarının termal verimliliğinin artırılmasıdır. Weber ve arkadaşları tarafından yüksek sıcaklıktaki hava ile büyük miktarlarda yakıtların yakılmasına yönelik yeni bir teknoloji geliştirilmiştir. Diğer proseslere oranla daha yavaş olmasına rağmen bu teknolojinin yüksek ve uniform radyoaktif ısı akılarını sağladığ belirlenmiştir [6].

Hava kalitesini artırmak adına gelişmiş ülkelerde (Avrupa Birliği ülkeleri, ABD) ciddi yasal düzenlemeler bulunmaktadır. Ülkemizde ise Çevre Kanununca Alınması Gereken İzin ve Lisanslar Hakkında Yönetmelik, Büyük Yakma Tesisleri Yönetmeliği, Sanayi Kaynaklı Hava Kirliliğinin Kontrolü Yönetmeliği, Atıkların Yakılmasına İlişkin Yönetmelik bu konuya yönelik getirilen yasal düzenlemelerdir. 2008 Avrupa Hava Kalitesi Direktifi (AQD, 2008/50/EC), ülkeleri bir dizi model ve monitör (izleme) sisteminin kullanılmasına teşvik 
etmektedir. Ayrıca üye devletlerin hava kalitesi sınır değerlerinin sağlanmadığı bölgelerde uygun hava kalitesi planlarını tasarlaması gerekmektedir. Bagayev ve Lochard tarafından, hava kirliliği düzenlemelerinin sıkılığındaki süreç, Hava Kalitesi Çerçeve Direktifi (AB, 1996) temel alınarak değerlendirilmiştir [7]. Thunis ve arkadaşları tarafından, AB'deki değerlendirme ve planlama araçları üzerinden bölgesel ve yerel ölçekli hava kalitesi modelleme uygulamaları değerlendirilmiştir. Mevcut uygulamalar arasındaki farklılıklar, AB'de bir uyumlaştırmanın gerekliliğini göstermiştir [8]. Hava kalitesi izlenmesi konusunda ülkelere ait bu farklı uygulamalar literatürde son dönemde yoğun olarak çalışılan bir konu haline gelmiştir. Guevara ve arkadaşları tarafından Meksika şehri metropol alanında hava kalitesinin modellenmesi için emisyon işletme sistemi geliştirilmiştir. Geliştirilen sistemde 2014 y1lı hava kirliliği en kötü durum senaryosu üzerinden çalışılmış ve sonuçlar önerilen sistemin hava kalitesi modellenmesinde kullanılabileceğini göstermiştir [9]. Chen ve arkadaşları tarafından hava kalitesi hedefinin sağlanması için birincil PM2.5 ve ikincil PM2.5 öncüllerin azaltılmasına yönelik modelleme yaklaşımı geliştirilmiştir. Model, Tayvan'da emisyon azaltılmasına yönelik pek çok senaryo üzerinden simüle edilmiş ve çalışmanın emisyon azaltılması çalışmalarına katkı sağlayacağı belirtilmiştir [10]. Jensen ve arkadaşları tarafından Danimarka'daki tüm sokaklar için yüksek çözünürlüklü çok kademeli hava kalitesi modellemesi yapılmıştır. 2012'deki NO2, PM2.5, PM10 yıllık konsantrasyonları Danimarka'daki 2.4 milyon adres için modellenmiştir. Genel olarak model tahmin değerlerinin tüm bileşenler için doğru bir harita sağladığı belirlenmiştir [11]. Zhang ve arkadaşları tarafından Hong Kong ve Çin Pearl River Deltası sınır ötesi hava kalitesi yönetimi için ayarlanabilir emisyon envanteri ile bir modelleme sistemi geliştirilmiştir. Simülasyonlar, emisyon kontrolü ile hava kalitesi iyileştirmesinin sınırlı ölçüde olduğunu göstermiş, bölgesel işbirliğinin daha etkili olacağı vurgulanmıştır [12]. Taylan tarafından hava kalitesi tahmini için yapay zeka tekniği kullanılarak ozon konsantrasyonunun modellenmesi ve analizi yapılmıştır. Cidde kenti için Suudi Arabistan'ın hava kalitesi standartları kullanılarak ozon konsantrasyon seviyesi, atmosferik basınç, sıcaklık, bağıl nem ve $\mathrm{NO}_{\mathrm{x}}$ faktörleri kullanılarak modellenmiştir. Sonuçlar, bu model yaklaşımının daha gerçek sonuçlar verebildiğini göstermiştir [13].

Ülkemizde, hava kirleticilerinin muhtemel etkilerini araştıran ve bu etkileri yerel ölçekte değerlendiren herhangi bir çalışma bulunmamaktadır. Bu çalışmada, Çevre ve Şehircilik Bakanlığı'nın Ulusal Hava Kalitesi İzleme Ağı verileri kullanılarak ALOHA yazılımı yardımı ile hava kirletici bileşenlerinin noktasal ve anlık muhtemel etkileri araştırılmıştır. Analizler, Kocaeli-Dilovası'nda, 2010 ve 2017 yılı için ayrı ayrı yürütülmüş ve değerlendirilmiştir. 


\section{MATERYAL VE METOD}

\subsection{Ulusal Hava Kalitesi İzleme A $\breve{g}$}

Hava kirliliğinin doğru bir şekilde ölçülmesi, hava kalitesinin daha iyi duruma getirilebilmesi amacıyla, Çevre ve Şehircilik Bakanlığı tarafından 2005-2007 yıllarında ülkemizde her ilde hava kalitesi ölçüm istasyonu kurulmuştur ve istasyon sayısı mevcut hali ile 195 sabit, 4 mobil istasyona ulaşmıştır. Bakanlık tarafından ayrıca Ulusal Hava Kalitesi İzleme Ağı (UHKİA) oluşturulmuştur [14]. Hava Kalitesi İzleme İstasyonları web sitesi ile izleme ağına iletilen verilerin eşzamanlı olarak yayınlanması sağlanmaktadır. Coğrafi Bilgi Sistemi (CBS) haritası üzerindeki istasyon noktalarında hava kalitesi indeksi kolaylıkla gözlenmektedir. Sayfada, hava kalitesi indeksi iyi, orta, hassas, sağlıksız, okötü, @tehlikeli şeklinde sınıflandırılmıştır. Bu sınıflandırma, ABD Çevre Koruma Ajansı (EPA) tarafından yayınlanan Hava Kalitesi İndeksi [15]'nin ulusal mevzuatımız ve sınır değerlerimize uyarlanmasıyla elde edilmiştir (Tablo 1).

Tablo 1. Ulusal Hava Kalitesi İndeksi [14]

\begin{tabular}{|c|c|c|c|c|c|c|}
\hline Sınıflandırma & $\begin{array}{c}\text { Hava Kalite } \\
\text { İndeksi }\end{array}$ & $\begin{array}{c}\mathrm{SO}_{2}\left[\mu \mathrm{g} / \mathrm{m}^{3}\right] \\
1 \text { saatlik } \\
\text { ortalama }\end{array}$ & $\begin{array}{c}\mathrm{NO}_{2}\left[\mu \mathrm{g} / \mathrm{m}^{3}\right] \\
1 \text { saatlik ortalama }\end{array}$ & $\begin{array}{c}\mathrm{CO}\left[\mu \mathrm{g} / \mathrm{m}^{3}\right] \\
8 \text { saatlik ortalama }\end{array}$ & $\begin{array}{c}\mathrm{O}_{3}\left[\mu \mathrm{g} / \mathrm{m}^{3}\right] \\
8 \text { saatlik ortalama }\end{array}$ & $\begin{array}{l}\text { PM10 }\left[\mu \mathrm{g} / \mathrm{m}^{3}\right] \\
24 \text { saatlik ortalama }\end{array}$ \\
\hline $\mathbf{I y i}^{\mathbf{a}}$ & $0-50$ & $0-100$ & $0-100$ & $0-5500$ & $0-120$ & $0-50$ \\
\hline Orta $^{b}$ & $51-100$ & $101-250$ & $101-200$ & $5501-10000$ & $121-160$ & $51-100$ \\
\hline Hassas $^{\mathrm{c}}$ & $101-150$ & $251-500$ & $201-500$ & $10001-16000$ & $161-180$ & $101-260$ \\
\hline Sağlıksız ${ }^{d}$ & $151-200$ & $501-850$ & $501-1000$ & $16001-24000$ & $181-240$ & $261-400$ \\
\hline Kötii ${ }^{\mathrm{e}}$ & $201-300$ & $851-1100$ & $1001-2000$ & $24001-32000$ & $241-700$ & $401-520$ \\
\hline Tehlikelif & $301-500$ & $>1101$ & $>2001$ & $>32001$ & $>701$ & $>521$ \\
\hline
\end{tabular}

${ }^{\mathrm{a} H a v a}$ kalitesi memnun edici ve hava kirliliği az riskli veya hiç risk teşkil etmiyor.

bHava kalitesi uygun fakat alışılmadık şekilde hava kirliliğine hassas olan çok az sayıdaki insanlar için bazı kirleticiler açısından orta düzeyde sağlık endişesi oluşabilir.

'Hassas gruplar için sağlık etkileri oluşabilir. Genel olarak kamunun etkilenmesi olası değildir.

dHerkes sağlık etkileri yaşamaya başlayabilir, hassas gruplar için ciddi sağlık etkileri söz konusu olabilir.

eSağlık açısından acil durum oluşturabilir. Nüfusun tamamının etkilenme olasılığı yüksektir.

fSağlık alarmı-herkes daha ciddi sağlık etkileri ile karşılaşabilir.

Tablo 1'den 5 temel kirletici (PM10, $\mathrm{SO}_{2}, \mathrm{NO}_{2}, \mathrm{O}_{3}$ ve $\mathrm{CO}$ ) için hava kalitesi indeksi hesabının olduğu görülmektedir. Hava kirleticilerine ait indeks sınır değerlerinin ulusal ve AB mevzuatı ile karşılaştırılması Tablo 2’de verilmiştir.

Tablo 2'den $\mathrm{SO}_{2}, \mathrm{NO}_{2}$ ve PM10 konsantrasyon sınır değerleri toleransının AB'ne kıyasla ülkemizde daha yüksek olduğu görülmektedir. 
Tablo 2. İndeks sınır değerlerinin karşılaştırılması [14]

\begin{tabular}{|c|c|c|c|c|c|}
\hline Mevzuat & $\begin{array}{c}\mathrm{SO}_{2}\left[\mu \mathrm{g} / \mathrm{m}^{3}\right] \\
1 \text { saatlik ortalama }\end{array}$ & $\begin{array}{c}\mathrm{NO}_{2}\left[\mu \mathrm{g} / \mathrm{m}^{3}\right] \\
1 \text { saatlik ortalama }\end{array}$ & $\begin{array}{c}\mathrm{CO}\left[\mu \mathrm{g} / \mathrm{m}^{3}\right] \\
8 \text { saatlik ortalama }\end{array}$ & $\begin{array}{c}\mathrm{O}_{3}\left[\mu \mathrm{g} / \mathrm{m}^{3}\right] \\
\text { 8 saatlik ortalama }\end{array}$ & $\begin{array}{c}\text { PM10 }\left[\mu \mathrm{g} / \mathrm{m}^{3}\right] \\
24 \text { saatlik ortalama }\end{array}$ \\
\hline Ulusal & 410 & 270 & 10000 & 120 & 70 \\
\hline $\mathrm{AB}$ & 350 & 200 & 10000 & 120 & 50 \\
\hline
\end{tabular}

Hava Kalitesi İzleme İstasyonları web sitesinde yer alan dinamik tablo verisi üzerinden her bir coğrafi bölgeye ait istasyon noktalarından tarih saate göre $\mathrm{PM} 10, \mathrm{SO}_{2}, \mathrm{NO}, \mathrm{NO}_{2}, \mathrm{NO}_{\mathrm{x}}, \mathrm{O}_{3}$ ve CO hava kirleticilerine ait konsantrasyon $\left(\mu \mathrm{g} / \mathrm{m}^{3}\right)$ değerleri sayısal olarak görülmektedir. Kocaeli-Dilovası için 2010 ve 2017 yılına ait hava kirletici konsantrasyonları Tablo 3'de verilmiştir.

Tablo 3. Kocaeli-Dilovası hava kirletici konsantrasyonları $\left(\mu \mathrm{g} / \mathrm{m}^{3}\right)$

\begin{tabular}{lll}
\hline Hava kirletici & $\mathbf{2 0 1 0}$ & $\mathbf{2 0 1 7}$ \\
\hline PM10 & 73 & 42 \\
$\mathrm{CO}$ & 864 & 774 \\
$\mathrm{SO}_{2}$ & 28 & 49 \\
$\mathrm{NO}$ & 20 & 39 \\
$\mathrm{NO}_{2}$ & 62 & 92 \\
$\mathrm{NO}_{x}$ & 82 & 131 \\
$\mathrm{O}_{3}$ & 35 & 17 \\
\hline
\end{tabular}

PM10, CO ve $\mathrm{O}_{3}$ konsantrasyon değerlerinin 2017 yılında azaldığ 1 Tablo 3'den görülmektedir. 2010 yılı PM10 değeri orta hava sınıflandırmasında yer alırken, diğer hava kirletici bileşenleri her iki yıl için iyi hava sınıfında yer almaktadır.

\subsection{Modelleme Çalışmaları}

Modelleme çalışmaları hava kirletici gazlar için ALOHA yazılımı kullanılarak gerçekleştirilmiştir. ALOHA bir kimyasal tehlike modelleme yazılımıdır. Yazılımda, gerçek veya potansiyel kazalar için lokasyon, atmosferik seçim, kimyasal ve ilgili senaryo seçimine ait veri girişi ile tehlike bölgeleri belirlenmektedir. Bu yazılım ile toksik gaz bulutu, yanabilen gaz bulutu, BLEVE (Boiling Liquid Expanding Vapor Explosion), jet yangınları, havuz yangınları ve buhar bulutu patlamaları modellenebilmektedir.

Hava kirliliği, ülkemizde temelde 1sınma, endüstri ve ulaşım kaynaklıdır. Sanayinin yoğun olduğu Kocaeli-Dilovası'na ait hava kirletici konsantrasyonu değerleri üzerinden 2010 ve 2017 yılı için ayrı ayrı modelleme çalışmaları yürütülmüştür. Modelleme çalışmalarında, netlik belirtmediğinden PM10 ve $\mathrm{NO}_{\mathrm{x}}$ bileşenleri değerlendirilmemiştir. NFPA 704 standardına göre hava kirletici bileşenlerin potansiyel tehlikeleri Tablo 4'de verilmiştir. 
Tablo 4. Hava kirletici bileşenlerin potansiyel tehlikeleri

Bileşen Kodlu eşkenar dörtgen $\begin{array}{ll}\text { Potansiyel tehlike } \\ \text { Hemen dağılır ve yanar. }\end{array}$

Tablo 4'de görülen eşkenar dörtgenlerde ilgili kimyasal için kırmızı alan yanabilirlik tehlikesini, mavi alan sağlık tehlikesini (özellikle toksisite), sarı alan reaktiflik, beyaz alan ise o kimyasala ait spesifik bir tehlikeyi ifade etmektedir. Her bir tehlike için kodlama 0-4 aralığında yapılmaktadır ve 4 en şiddetli durumu belirtmektedir. Hava kirleticileri arasında tek yanıcı özellik CO kimyasalında gözlenmektedir. $\mathrm{O}_{3}$ ise en reaktif ve toksik etkiye sahip olan kimyasaldır.

Kocaeli ili atmosferik koşulları, rüzgar hızı: $2 \mathrm{~m} / \mathrm{s}$, hakim rüzgar yönü: güney doğu, hava kararlılık sınıfi: F, bulutluluk: parçalı, sıcaklık: $30^{\circ} \mathrm{C}$, inversiyon etkisi: yok, nem: $\% 70$ olarak yazılımda seçilmiştir. Etki mesafelerinin insan seviyesinde ve kentsel/ormanlık alan içinde hesaplanabilmesi üzerine yazılımda seçimler yapılmıştır. Her bir hava kirletici gaz, anlık boşalma senaryosu ile doğrudan kaynak olarak modellenmiştir. CO hava kirleticisine ait yüksek basınç etkilerinin belirlenmesinde, buhar bulutu tutuşturucu kaynağının alev/kıvılcım ve detonasyon olması durumları ayrı senaryolar üzerinden çalışılmıştır. 


\section{BULGULAR VE TARTIŞMA}

\subsection{Yanma ve Patlama Etkileri}

Hava kirleticilerin potansiyel tehlike özellikleri dikkate alındığında (Tablo 2), KocaeliDilovası'nda seçilen atmosferik koşullarda sadece CO için toksik bölge, yanabilir bölge ve yüksek basınç etkilerinin olduğu bölgede etki mesafesi değerleri belirlenmiştir. (Şekil 1)

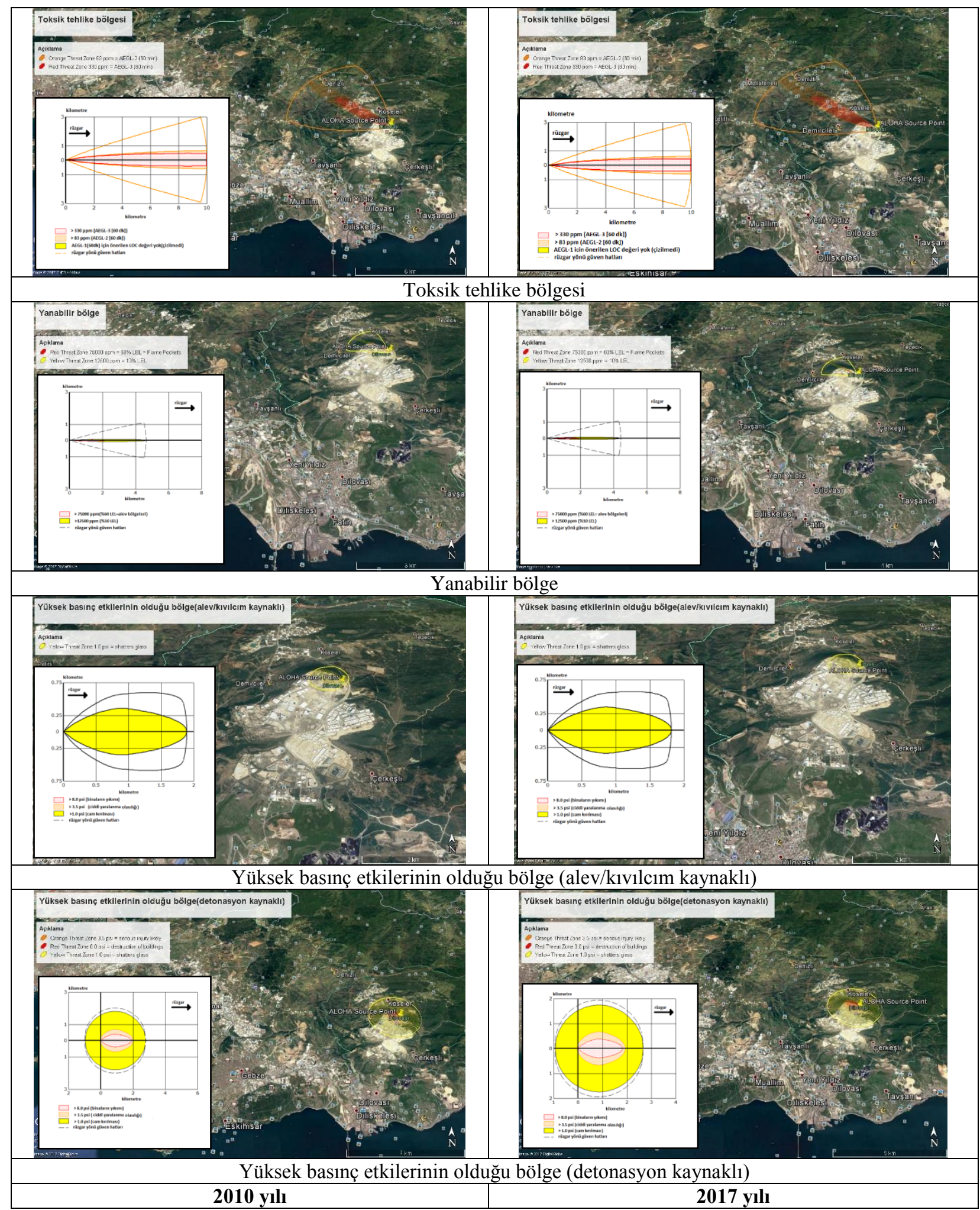

Şekil 1. CO hava kirleticisine ait tehlike bölgeleri 
Şekil 1'den CO için toksik bölge ve yanabilir bölge tehlike bölgelerinin yıllara göre ciddi bir değişim göstermediği görülmektedir. Bölgedeki hakim rüzgar yönü (güney-doğu) toksik ve yanabilir tehlike bölgelerini, popülasyonun daha az olduğu alanlara yöneltmiştir. Bölge için bu bir avantajdır, ancak iklim değişikliğinin yaşandığı şu günlerde çevre düzenlemelerinin tüm rüzgar yönü dikkate alınarak yapılması ilerleyen dönem için daha faydalı olacaktır. Yüksek basınç etkilerinin olduğu bölge ise rüzgar yönüne bağlı bir değişim göstermemiştir. Yüksek basınç etkilerinin olduğu bölge için elde edilen etki alanı şekillerinde tutuşturucu kaynağına göre değişimin olduğu gözlenmiştir. Yıllara göre ciddi bir değişim olmamakla birlikte detonasyon kaynaklı patlama etki alanının daha büyük olduğu belirlenmiştir. Buhar bulutu tutuşturucu kaynağı alev/kıvılcım olduğunda yazılımda ortamın sıkışıklık/konjesyon durumunun seçimi yapılabilmektedir. Model çalışmasında, sıkışık ve yürümenin zor olduğu boru bağlantı dizisi ya da sık ormanlık alan varsayımı yapılmıştır. Ortam engelinin etki mesafesi üzerine etkisi kimyasala göre değişmektedir [16]. Buhar bulutu tutuşturucu kaynağı detonasyon olduğunda yazılımda konjesyon seçimi yapılamamaktadır. Buhar bulutu tutuşturucu kaynağının alev/kıvılcım ve detonasyon olduğu her iki durum için de buhar bulutu tutuşma süresinin bilinmediği (tüm olası tutuşma sürelerinin bileşimi olan tehlike bölgesi gösterilir) seçimi yapılmıştır. Tutuşma süresi, ateşleme kaynağının uygulanması ile yakıtın kendi kendine sürekli yanması arasındaki zaman olarak tanımlanmaktadır. CO hava kirleticisine ait etki mesafeleri Tablo 5'de verilmiştir.

Tablo 5. CO hava kirleticisine ait etki mesafeleri

\begin{tabular}{|c|c|c|c|c|c|c|c|c|}
\hline \multicolumn{3}{|c|}{ Yanabilir bölge } & \multicolumn{3}{|c|}{$\begin{array}{l}\text { Yüksek basınç etkilerinin olduğu bölge } \\
\text { (alev, kıvılcım kaynaklı) }\end{array}$} & \multicolumn{3}{|c|}{$\begin{array}{l}\text { Yüksek basınç etkilerinin olduğu bölge } \\
\text { (detonasyon kaynaklı) }\end{array}$} \\
\hline \multicolumn{9}{|c|}{2010 yılı } \\
\hline $\begin{array}{c}\text { Kirmiz1 } \\
\text { (>75000 ppm, } \\
\text { \%60 LEL) }\end{array}$ & Turuncu & $\begin{array}{c}\text { Sar1 } \\
(>12500 \mathrm{ppm}, \\
\% 60 \text { LEL })\end{array}$ & $\begin{array}{l}\text { Kirmızi } \\
(>8.0 \text { psi) }\end{array}$ & $\begin{array}{l}\text { Turuncu } \\
(>3.5 \mathrm{psi})\end{array}$ & $\begin{array}{c}\text { Sarı } \\
(>1.0 \mathrm{psi})\end{array}$ & $\begin{array}{l}\text { Kirmızı } \\
(>8.0 \text { psi) }\end{array}$ & $\begin{array}{l}\text { Turuncu } \\
(>3.5 \mathrm{psi})\end{array}$ & $\begin{array}{c}\text { Sarı } \\
(>1.0 \mathrm{psi})\end{array}$ \\
\hline $2.2 \mathrm{~km}$ & - & $4.7 \mathrm{~km}$ & - & - & $1.9 \mathrm{~km}$ & $1.9 \mathrm{~km}$ & $2.0 \mathrm{~km}$ & $2.8 \mathrm{~km}$ \\
\hline \multicolumn{9}{|c|}{2017 yılı } \\
\hline $\begin{array}{c}\text { Kirmız1 } \\
\text { (75000 ppm, } \\
\text { \%60 LEL) }\end{array}$ & Turuncu & $\begin{array}{c}\text { Sarı } \\
(>12500 p p m, \\
\text { \%60 LEL) }\end{array}$ & $\begin{array}{l}\text { Kırmızı } \\
(>8.0 \mathrm{psi})\end{array}$ & $\begin{array}{l}\text { Turuncu } \\
(>3.5 \mathrm{psi})\end{array}$ & $\begin{array}{c}\text { Sarı } \\
(>1.0 \mathrm{psi})\end{array}$ & $\begin{array}{l}\text { Kırmızı } \\
(>8.0 \text { psi) }\end{array}$ & $\begin{array}{l}\text { Turuncu } \\
(>3.5 \mathrm{psi})\end{array}$ & $\begin{array}{c}\text { Sarı } \\
(>1.0 \text { psi })\end{array}$ \\
\hline $2.1 \mathrm{~km}$ & - & $4.5 \mathrm{~km}$ & - & - & $1.8 \mathrm{~km}$ & $1.8 \mathrm{~km}$ & $1.9 \mathrm{~km}$ & $2.7 \mathrm{~km}$ \\
\hline
\end{tabular}

Tablo 5'den CO konsantrasyonunun 2017 y1lında azalmasına bağlı olarak etki mesafesi değerlerinin tüm bölgeler için azaldığı görülmektedir. En geniş etki mesafesi değerleri ise toksik bölge (>10 km) için belirlenmiştir. Yanabilir bölgede, kırmızı (>75000 ppm, \%60 LEL) ve sarı (>12500 ppm, \%60 LEL) tehlike bölgeleri için etki mesafeleri belirlenmiştir. LEL (Lower Explosion Limit-Alt Patlama Sınırı) hava içinde olması gereken minimum yanıcı madde buhar oranıdır [16]. Alev/kıvılcım kaynaklı yüksek basınç etkisi için sadece cam kırılması (>1.0 psi) etkisi belirlenirken; detonasyon kaynaklı yüksek basınç etkileri için bina yıkılması, ciddi yaralanma olasılığı ve cam kırılması etkilerinin tamamı belirlenmiştir. 
Detonasyon, bir süpersonik ekzotermik cepheyi içeren ve doğrudan önündeki şok cephesini sürükleyen bir ortam vasıtasıyla hızlanan yanma türüdür. Parlama noktası çok düşük olan CO için detonasyon patlamasına ait dalga sistemi gözlemlenebilmektedir. Patlama sonucunda, çeşitli gazlar, damla sisleri veya toz süspansiyonları oluşmaktadır. Detonasyon, geleneksel yanma oranlarının biraz altındaki bir bileşimdeki bir yakıt ve oksidant karışımı ile ilişkilidir $[17,18]$.

\subsection{Toksik Etkiler}

$\mathrm{CO}$ dışında diğer hava kirleticilerine $\left(\mathrm{SO}_{2}, \mathrm{NO}, \mathrm{NO}_{2}, \mathrm{O}_{3}\right)$ ait yalnız toksik etkiler belirlenmiş ve tehlike bölgeleri Şekil 2' de sunulmuştur.

Şekil 2'den tehlike bölgesi etki alanlarının diğer tüm hava kirleticileri için yıllara göre belirgin değişim göstermediği görülmektedir. Bölgenin hakim rüzgar yönü (güney-doğu), diğer hava kirleticilerine ait toksik tehlike bölgelerini popülasyon ve yerleşim birimlerinden uzak mevkilere yönlendirmiştir. Bu durum, insan sağlığı açısından oldukça avantajlıdır. Toksik bölgede $\mathrm{NO}_{2}, \mathrm{CO}, \mathrm{SO}_{2}$ için AEGL; $\mathrm{NO}$ ve $\mathrm{O}_{3}$ için PAC değerleri üzerinden etki alanları belirlenmiştir. PAC (Protective Action Criteria for Chemicals-Kimyasallar için Koruyucu Eylem Kriterleri) değerleri üç genel kamu maruz kalma k1lavuz sistemini (AEGLs, ERPGs, and TEELs) ifade etmektedir. PAC, i) Dönem sonu, 60 dakika AEGL değerleri, ii) Ara dönem, 60 dakika AEGL değerleri, iii) ERPG değerleri, iv) TEEL değerleri şeklinde bir hiyerarşiye sahiptir. İlgili kimyasal için bu sıraya göre toksik etki alanı elde edilmektedir. Toksik bölgede, PAC ifadesinin görülmesi ise ilgili kimyasala ait TEEL değerlerini ifade etmektedir [16]. Diğer hava kirleticilerine ait etki mesafeleri Tablo 6' da verilmiştir.

Tablo 6. Diğer hava kirleticilerine $\left(\mathrm{SO}_{2}, \mathrm{NO}, \mathrm{NO}_{2}, \mathrm{O}_{3}\right)$ ait etki mesafeleri

\begin{tabular}{|c|c|c|c|c|c|c|c|c|c|c|c|}
\hline \multicolumn{3}{|c|}{$\mathrm{SO}_{2}$} & \multicolumn{3}{|c|}{ NO } & \multicolumn{3}{|c|}{$\mathrm{NO}_{2}$} & \multicolumn{3}{|c|}{$\mathbf{O}_{3}$} \\
\hline \multicolumn{12}{|c|}{2010 yılı } \\
\hline $\begin{array}{c}\text { Kırmız1 } \\
(>30 \mathrm{ppm})\end{array}$ & $\begin{array}{c}\text { Turuncu } \\
(>0.75 \mathrm{ppm})\end{array}$ & $\begin{array}{c}\text { Sarı } \\
(>0.20 \mathrm{ppm})\end{array}$ & $\begin{array}{c}\text { Kirmız1 } \\
(>20 \mathrm{ppm})\end{array}$ & $\begin{array}{l}\text { Turuncu } \\
(>12 \mathrm{ppm})\end{array}$ & $\begin{array}{c}\text { Sar1 } \\
(>0.5 \mathrm{ppm})\end{array}$ & $\begin{array}{c}\text { Kirmız1 } \\
(>20 \mathrm{ppm})\end{array}$ & $\begin{array}{l}\text { Turuncu } \\
(>12 \mathrm{ppm})\end{array}$ & $\begin{array}{c}\text { Sar1 } \\
(>0.5 \mathrm{ppm})\end{array}$ & $\begin{array}{c}\text { Kirmızı } \\
(<10 \mathrm{ppm})\end{array}$ & $\begin{array}{c}\text { Turuncu } \\
(>1.0 \mathrm{ppm})\end{array}$ & $\begin{array}{c}\text { Sar1 } \\
(>0.24 \mathrm{ppm})\end{array}$ \\
\hline $5.2 \mathrm{~km}$ & $>10 \mathrm{~km}$ & $>10 \mathrm{~km}$ & $>10 \mathrm{~km}$ & $>10 \mathrm{~km}$ & $>10 \mathrm{~km}$ & $>10 \mathrm{~km}$ & $>10 \mathrm{~km}$ & $>10 \mathrm{~km}$ & $>10 \mathrm{~km}$ & $>10 \mathrm{~km}$ & $>10 \mathrm{~km}$ \\
\hline \multicolumn{12}{|c|}{2017 yılı } \\
\hline $\begin{array}{c}\text { Kırmızı } \\
(>30 \mathrm{ppm})\end{array}$ & $\begin{array}{c}\text { Turuncu } \\
(>0.75 \mathrm{ppm})\end{array}$ & $\begin{array}{c}\text { Sarı } \\
(>0.20 \mathrm{ppm})\end{array}$ & $\begin{array}{c}\text { Kırmızı } \\
(>20 \mathrm{ppm})\end{array}$ & $\begin{array}{c}\text { Turuncu } \\
(>12 \mathrm{ppm})\end{array}$ & $\begin{array}{c}\text { Sarı } \\
(>0.5 \mathrm{ppm})\end{array}$ & $\begin{array}{c}\text { Kirmızı } \\
(>20 \mathrm{ppm})\end{array}$ & $\begin{array}{l}\text { Turuncu } \\
(>12 \mathrm{ppm})\end{array}$ & $\begin{array}{c}\text { Sarı } \\
(>0.5 \mathrm{ppm})\end{array}$ & $\begin{array}{c}\text { Kırmızı } \\
(<10 \mathrm{ppm})\end{array}$ & $\begin{array}{c}\text { Turuncu } \\
(>1.0 \mathrm{ppm})\end{array}$ & $\begin{array}{c}\text { Sarı } \\
(>0.24 \mathrm{ppm})\end{array}$ \\
\hline $6.6 \mathrm{~km}$ & $>10 \mathrm{~km}$ & $>10 \mathrm{~km}$ & $>10 \mathrm{~km}$ & $>10 \mathrm{~km}$ & $>10 \mathrm{~km}$ & $>10 \mathrm{~km}$ & $>10 \mathrm{~km}$ & $>10 \mathrm{~km}$ & $8.1 \mathrm{~km}$ & $>10 \mathrm{~km}$ & $>10 \mathrm{~km}$ \\
\hline
\end{tabular}

Tablo 6'dan $\mathrm{NO}$ ve $\mathrm{NO}_{2}$ için yıllara göre etki mesafelerinin değişmediği görülmüş ve tüm mesafeler $>10 \mathrm{~km}$ olarak belirlenmiştir. Bu hava kirletici konsantrasyonları, hava kalitesi sınır değerleri içinde kalsa dahi, modellemenin yapıldığı anlık noktasal bir boşalma durumunda son derece zehirli oldukları için geniş etkiler vermiştir. $\mathrm{O}_{3}$ konsantrasyonun azalmasına bağlı olarak 2017 yılında kırmızı bölge (>10 ppm, PAC-3) etki mesafesi 8.1 km’ye düşmüştür. O , $_{3}$, solunum sisteminin tahriş olmasına, akciğer fonksiyonlarında azalmalara, iltihaplanmaya neden olan son derece zehirli bir kimyasaldır. 


\section{S. Cetinyokus, Aksaray University Journal of Science and Engineering, 1(2) (2017) 121-133.}

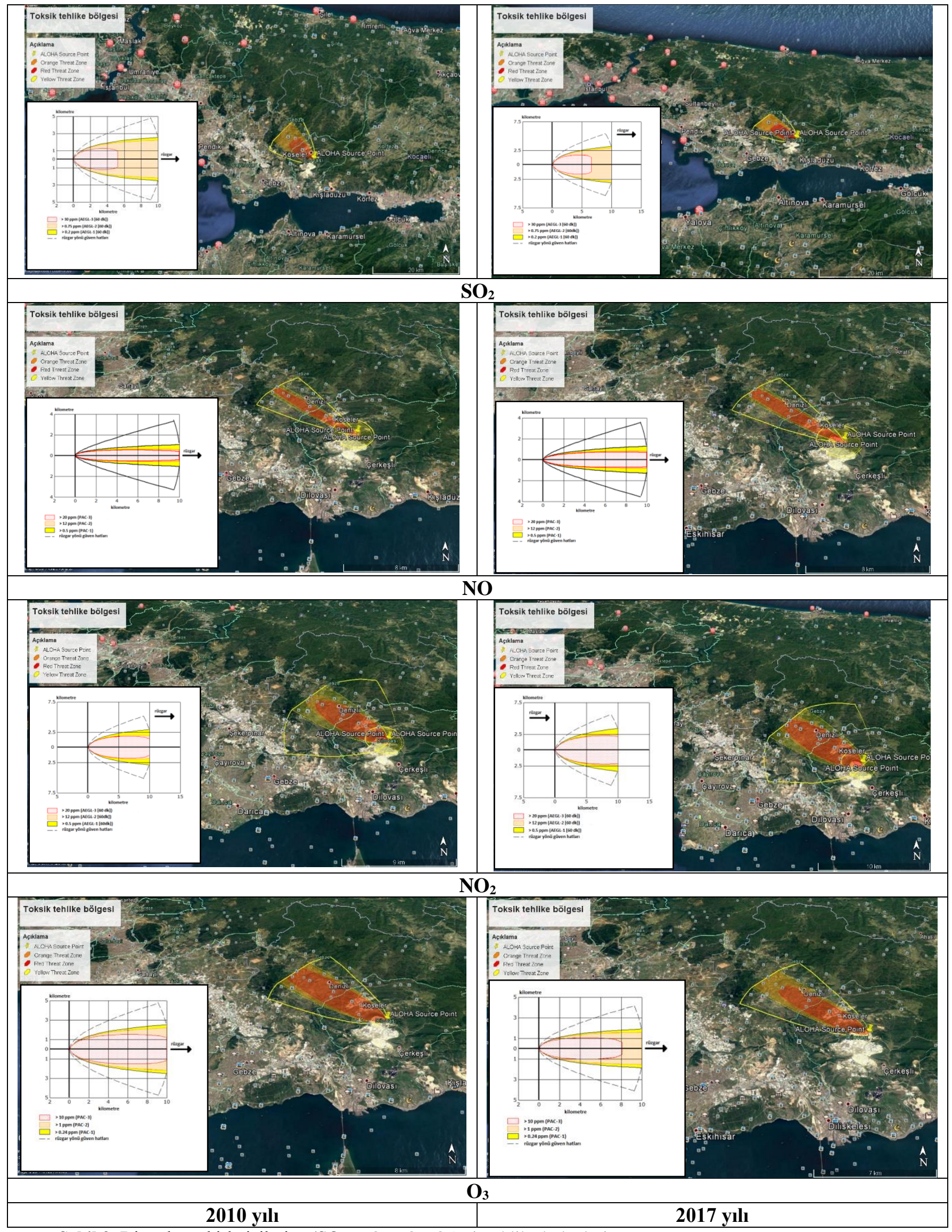

Şekil 2. Diğer hava kirleticilerine $\left(\mathrm{SO}_{2}, \mathrm{NO}, \mathrm{NO}_{2}, \mathrm{O}_{3}\right)$ ait tehlike bölgeleri 
$\mathrm{SO}_{2}$ için ise aynı şekilde kırmızı bölge ( > 30 ppm, AEGL-3) etki mesafesi 2017 yılında $6.6 \mathrm{~km}$ olarak daha düşük belirlenmiştir. $\mathrm{SO}_{2}, \mathrm{OH}$ radikalleriyle veya $\mathrm{O}_{3}$ ve $\mathrm{H}_{2} \mathrm{O}_{2}$ ile oksitlendiği durumlarda daha geniş mesafelere yayılmaktadır. $\mathrm{SO}_{2}$ 'nin etkileri sadece yerel değildir küreseldir [3]. Etki mesafeleri üzerine özellikle toksik bölgede atmosferik kararlılık sınıfının önemli etkilerinin olduğu bilinmektedir [16]. Atmosferik kararlılık 6 sınıfa ayrılan Pasquill model ile tanımlanmaktadır. Çok kararsız atmosferler A, B; nötr atmosferler C, D ve çok kararlılar E, F şeklinde sınıflandırılmaktadır. Atmosfer kararlıyken, kirliliğin dikey olarak dağılma eğilimi düşüktür [19]. Model çalışmalarında en kötü durum senaryosu düşünülerek F hava kararlılık sınıfı seçimi yapılmıştır.

\section{SONUÇLAR}

Hava kirleticilerinin, 2010 ve 2017 yılı konsantrasyonları dikkate alınarak KocaeliDilovası'nda muhtemel etkilerinin belirlenmesi için ALOHA yazılımı kullanılmıştır. Tüm hava kirleticilerinin hava kararlılık sınıfı iyi sınıfta yer almasına rağmen, anlık boşalma senaryosu üzerinden ciddi etkilere yol açabileceği belirlenmiştir. Tüm hava kirleticilerinin toksik etkilere neden olduğu gösterilmiştir. Bölgedeki hakim rüzgar yönü, toksik tehlike bölgelerini popülasyonun az olduğu mevkilere yönlendirmesi yönü ile avantajlı bulunmuştur. Toksik etki mesafelerinin kimyasala ait ilgili kamu maruz kalma k1lavuz sistemine (AEGLs, ERPGs, and TEELs) göre belirlendiği görülmüştür. Sadece CO hava kirleticisi için yanma, patlama ve toksik etkiler bir arada gözlemlenmiştir. Tutuşturucu kaynağına (alev/kıvılcım ve detonasyon) bağlı olarak patlama etki alanları ve mesafelerinin değiştiği gösterilmiştir. 2017 yılında hava kirleticilerden $\mathrm{CO}$ ve $\mathrm{O}_{3}$ konsantrasyonunun azalmasına bağlı olarak etki mesafeleri değerlerinin düştüğü belirlenmiştir. Çalışmanın, hava kirleticilerinin yerel düzeyde muhtemel etkilerinin belirlenmesi yönünde yürütülecek çalışmalara örnek teşkil edeceği düşünülmektedir. Hava kalitesinin ölçümler ve yasal düzenlemeler ile takibi yanında, hava kirleticilerinin muhtemel etkilerinin bilinmesiyle alınacak çeşitli önlemler özellikle insan sağlığı açısından oldukça önemlidir. Bu konunun, acil durum planları ile birlikte değerlendirilmesi, ilgili diğer özel/kamu kurum kuruluşları, üniversiteler ile ortak çalışmalar üzerinden yürütülmesi önerilebilir.

\section{KAYNAKLAR}

[1] N. Künzli, R. Kaiser, S. Medina, M. Studnicka, O. Chanel, P. Filliger, M. Herry, F. Horak Jr, V. Puybonnieux-Texier, P. Quénel, J. Schneider, R. Seethaler, J.C. Vergnaud, H. Sommer, Public-health impact of outdoor and traffic-related air pollution: a European assessment. Lancet 356 (2000) 795-801.

[2] P.D. Hien, P.D. Loc, N.V. Dao, Air pollution episodes associated with East Asian winter monsoons. Sci. Total Environ. 409 (2011) 5063-5068. 
[3] S.M. Serbula, J.S. Milosavljevic, A.A. Radojevic, J.V. Kalinovic, T.S. Kalinovic, Extreme air pollution with contaminants originating from the mining-metallurgical processes. Sci. Total Environ. 586 (2017) 1066-1075.

[4] H. Zhang, Y. Wang, T.W. Park, Y. Deng, Quantifying the relationship between extreme air pollution events and extreme weather events. Atmos. Res. 188 (2017) 64-79.

[5] V.S. Bachtiar, S. Raharjo, Y. Ruslinda, F. Hayati, D.R. Komala, Mapping of ozone gas $\left(\mathrm{O}_{3}\right)$ concentrations in Padang City. Procedia Eng. 125 (2015) 291-297.

[6] R. Weber, S. Orsino, N. Lalllemant, A.D. Verlaan, Combustion of natural gas with hightemperature air and large quantities of flue gas. Proceedings of the Combustion Institute, 28 (2000) 1315-1321.

[7] I. Bagayev, J. Lochard, EU air pollution regulation: A breath of fresh air for Eastern European polluting industries? J. Environ. Econ. and Manage. 83 (2017) 145-163.

[8] P. Thunis, A. Miranda, J.M. Baldasano, N. Blond, J. Douros, A. Graff, S. Janssen, K. JudaRezlerh, N. Karvosenoja, G. Maffeis, A. Martilli, M. Rasoloharimahefa, E. Real, P. Viaene, M. Volta, L. White, Overview of current regional and local scale air quality modelling practices: Assessment and planning tools in the EU. Environ. Sci. Policy. 65 (2016) 1321.

[9] M. Guevara, C. Tena, A. Soret, K. Serradell, D. Guzmán, A. Retama, P. Camacho, M. Jaimes-Palomera, A. Mediavilla, An emission processing system for air quality modelling in the Mexico City metropolitan area: Evaluation and comparison of the MOBILE6.2Mexico and MOVES-Mexico traffic emissions. Sci. Total Environ. 584-585 (2017) 882900.

[10] T.F. Chen, K.H. Chang, C.Y. Tsai, Modeling approach for emissions reduction of primary PM2.5 and secondary PM2.5 precursors to achieve the air quality target. Atmos. Res. 192 (2017) 11-18.

[11] S.S. Jensen, M. Ketzel, T. Becker, J. Christensen, J. Brandt, M. Plejdrup, M. Winther, O.K. Nielsen, O. Hertel, T. Ellermann, High resolution multi-scale air quality modelling for all streets in Denmark. Transport. Res. D. 52 (2017) 322-339.

[12] C. Zhang, H. Lin, M. Chen, X. Zheng, R. Li, Y. Ding, A modelling system with adjustable emission inventories for cross-boundary air quality management in Hong Kong and the Pearl River Delta, China. Comput. Environ. Urban Syst. 62 (2017) 222-232.

[13] O. Taylan, Modelling and analysis of ozone concentration by artificial intelligent techniques for estimating air quality. Atmos. Environ. 150 (2017) 356-365.

[14] http://www.havaizleme.gov.tr (20.04.2017)

[15] https://www3.epa.gov/airnow/aqi_brochure_02_14.pdf (28.04.2017)

[16] S. Çetinyokuş, Sonuç analizi ile belirlenen etki mesafeleri üzerine atmosferik seçimlerin etkisi (ALOHA yazılımı). Afyon Kocatepe Üniv. Fen ve Müh. Bil. Der. 17(1) (2017) 209217.

[17] D.R. Stull, Monograph Series.10. A.I. Chem. E., 73 (1977).

[18] P. Urben, L. Bretherick, (London: Butterworths, ISBN 978-0-12-372563-9, 1979).

[19] S. Çetinyokuş, M.A. Alkan, Endüstri tesisleri için koruma alanlarının belirlenmesi. III. Tehlikeli Kimyasalların Yönetimi Sempozyumu ve Sergisi, pp. 105-118, Mayıs 2015, Ankara, Türkiye. 